\title{
APPLICATION OF FUZZY SETS IN AN EXPERT SYSTEM FOR TECHNOLOGICAL PROCESS MANAGEMENT
}

\author{
JOSEF TOŠENOVSKÝ, BŘETISLAV KRČEK, LENKA \\ MONSPORTOVÁ, FILIP TOŠENOVSKÝ
}

\section{INTRODUCTION}

Automation of technological processes requires a computer simulation of the process operator's work. Such an approach is very successful in many cases, and the computer-based management is equally good or even better than manual management. However, there are also many examples of simulations which do not achieve the managerial level performed by man as an operator, no matter how complex these simulations are. Such problems occur, for instance, in processes whose outcome strongly depends on the operator's experience.

Application of expert systems (ES) is one of the ways how to exploit human experience when trying to describe the managerial issues mathematically during the automation (Kelemen \& Linday, 1996; Popper \& Kelemen, 1989; Bělohlávek \& Novák, 2002). Table 1 presents advantages of process management based on ES as compared to the management run by an expert.

Table 1 - Advantages of process management based on ES

\begin{tabular}{|l|l|}
\hline \multicolumn{1}{|c|}{ Expert } & \multicolumn{1}{c|}{ ES } \\
\hline $\begin{array}{l}\text { Experts who are off active duty for } \\
\text { some time lose some of their skills. }\end{array}$ & $\begin{array}{l}\text { ES can be switched off and switched on } \\
\text { again without any loss of its managerial } \\
\text { capabilities. }\end{array}$ \\
\hline $\begin{array}{l}\text { Transferring knowledge from an expert } \\
\text { to another person is a long process. }\end{array}$ & $\begin{array}{l}\text { Knowledge transfer means copying a } \\
\text { computer program only. }\end{array}$ \\
\hline $\begin{array}{l}\text { It is difficult to record or preserve } \\
\text { knowledge of an expert. }\end{array}$ & Documentation is held easily. \\
\hline Expert's work is costly. & Expenses on ES operations are low. \\
\hline There is a shortage of experts. & Availability of ES is high. \\
\hline
\end{tabular}

On the other hand, complete elimination of man has many disadvantages. Some of the most important ones are shown in Table 2. 
Table 2 - Disadvantages of process management based on ES

\begin{tabular}{|l|l|}
\hline \multicolumn{1}{|c|}{ Expert } & \multicolumn{1}{c|}{ ES } \\
\hline An expert accustoms to changes. & ES does not change. \\
\hline $\begin{array}{l}\text { An expert learns and develops their } \\
\text { skills. }\end{array}$ & ES does not develop. \\
\hline An expert has common sense. & ES does what it is programmed to do. \\
\hline
\end{tabular}

ES cannot be always used. It can be used only if certain prerequisites are met. These are:
a) The essence of the problem is known,
b) Managerial procedures do not require common sense, which is typically used when managerial steps change very often,
c) The problem is not too complex nor too simple,
d) Managerial procedures are intellectual in character, not manual,
e) Experts for the given problem are available,
f) The experts should be in agreement on major issues relating to the process.

The so-called decision rules constitute one of the key stages when creating an ES. These rules are based on experts' experience, and it is in this stage that difficulties arise because experts often use terminology which is very hard to formalize. An example of such terminology is the statement:

„If the pressure is high, we will lower the temperature a little bit.“

How to express ,high" and „, little bit"?

If top-class cooks described their "technology“ of preparing meals, they would certainly use many similar terms, such as: a pinch of salt, a bit of oil, steam slightly, etc. It wouldn't be easy to simulate such instructions. An appropriate way to formalize this terminology may, however, be found in the fuzzy set concept (Novák, 1986; Lin, He, and Qian, 2010; Wang et al. 2010).

\section{FUZZY SETS IN EXPERT SYSTEMS}

When defining ,a standard“ set, the elements of the set are listed individually, or distinctive features of the elements are defined. This can be done in many ways. One way is to use the so-called characteristic function $\chi_{A}(x)$. This function basically represents a logic statement, taking on the value $\chi_{A}(x)=1$ if $x \in A, x$ 
being an element of the universe $U$ (true statement), or $\chi_{A}(x)=0$ if $x \notin A$. (false statement). Thus, $\chi_{A}(x)$ maps $U$ on $\{0,1\}$.

Fuzzy sets approach generalizes the standard set approach: every element $x$ of $U$ is assigned a number from the interval $\langle 0,1\rangle$, a membership degree describing the weight with which $x$ belongs to the set $A$. We shall denote such value $A x$. The pair $(x, A x)$ forms a fuzzy set. Graphical depiction of the points $(x, A x)$ forms a membership function.

We depict the membership function as a trapezoid in this paper, according to Figure 1. The height of the trapezoid is one, and four defining points are denoted generally $a, b, c, d$. Of course, it is possible that $b=c$, for instance, in which case the graph leads to a triangle, or $a=b$ and $c=d$, which results in a rectangle, etc.

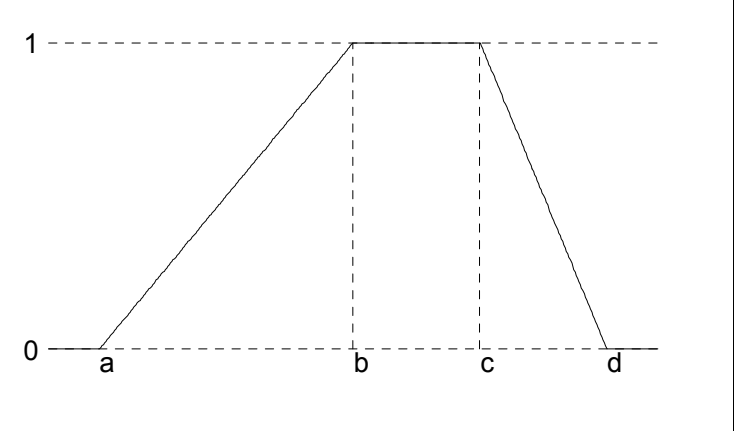

Figure 1 - Membership function

Combining experience of an expert and fuzzy sets approach, which enables us to describe the expert's language, we may simulate the management of a process.

In this paper, we aim to show a simulation using the aforementioned mathematical tools, taking as an example the management of a process with one input and one output. Generalization of such procedure to the case with more than one input is straightforward.

Let us assume that an output $Y$ is produced by an input $X$. Both $X$ and $Y$ fall into five categories: very small, small, standard, big, very big.

We define five levels to allow for a sufficient distinction of the levels of input and output. The levels represent fuzzy sets which must be defined, i.e. we must define when $X$ is small, standard, etc. Definition of $Y$ and $X$ as fuzzy sets is given in Table 3. 
Table 3 - Definition of fuzzy sets and regulation rules

\begin{tabular}{|c|c|c|c|c|c|c|c|c|}
\hline \multicolumn{5}{|c|}{ Measured output $Y$} & \multicolumn{4}{c|}{ Calculated regulation $X$} \\
\hline $\mathrm{a}$ & $\mathrm{b}$ & $\mathrm{c}$ & $\mathrm{d}$ & & $\mathrm{a}$ & $\mathrm{b}$ & $\mathrm{c}$ & $\mathrm{d}$ \\
\hline 0 & 0 & 0.4 & 0.6 & $\mathrm{X} 1$ & 0.9 & 0.9 & 1.0 & 1.1 \\
\hline 0.4 & 0.6 & 0.7 & 0.9 & $\mathrm{X} 2$ & 1.0 & 1.1 & 1.2 & 1.3 \\
\hline 0.7 & 0.9 & 1.0 & 1.1 & $\mathrm{X} 3$ & 1.2 & 1.3 & 1.3 & 1.4 \\
\hline 1.0 & 1.1 & 1.6 & 1.7 & $\mathrm{X} 4$ & 1.3 & 1.4 & 1.4 & 1.5 \\
\hline 1.6 & 1.7 & 2.0 & 2.0 & $\mathrm{X} 5$ & 1.4 & 1.5 & 1.5 & 1.6 \\
\hline
\end{tabular}

Graphical depiction of all the five fuzzy sets for $Y$ and $X$ is in figure 2 .
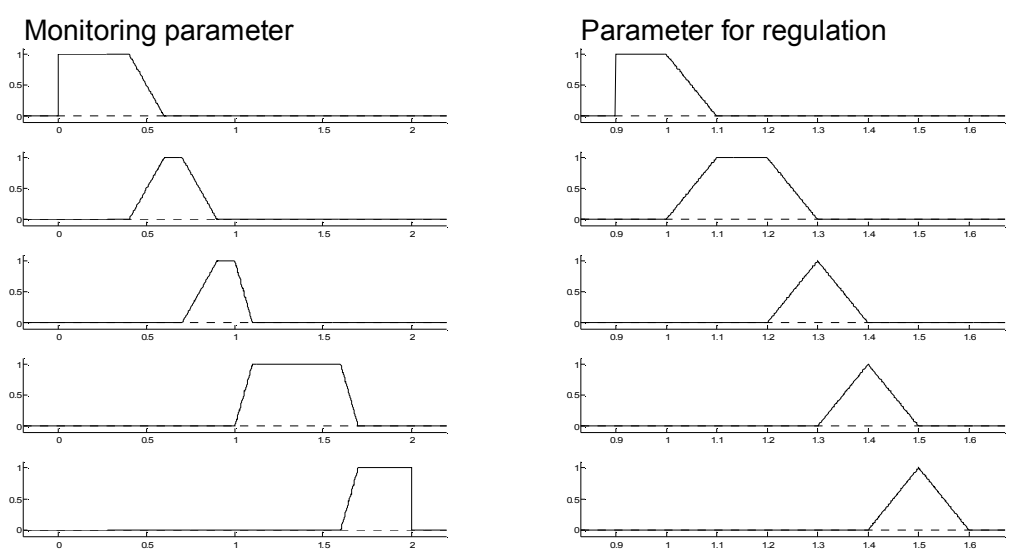

Figure 2 - Regulation rules based on table 3

The aim of the regulation is to keep the output $Y$ on a standard level, which is understood to be the values of $Y$ within the range $(0.9 ; 1.0)$. Based on the last measurement of $Y$, the manager performs an operative regulation $\mathrm{X}$ according to the following rules:

Selecting $X 1$ for $Y 1$, selecting $X 2$ for $Y 2, \ldots$, selecting $X 5$ for $Y 5$.

It is up to the operator to set the rules in a concrete simulated situation. Each line of Table 3 defines fuzzy sets ,very small, small, standard, big, very big“, and is a regulation rule at the same time. 


\section{PROCESS MANAGEMENT USING EXPERT SYSTEM}

How does an automatic process management simulating expert's work run? The program receives a measured value of the output $Y$. It is now to react to this value with an operation. Man evaluates the value in such a manner that he or she assigns it a level from the scale of levels used; in our case the levels are ranging from very small to very big. After that, the input $X$ is adjusted according to regulation rules.

Automatic activity, depicted in Figure 3, runs in the following steps:

a) the value of $Y$ is portrayed in all the fuzzy sets (in fig. $3 Y=0.768$, as an example),

b) a point of intersection of the corresponding vertical line with fuzzy set graphs is found,

c) the point of intersection is transfered into the fuzzy set graph of the input $X$,

d) the graph is reduced as depicted,

e) the resulting graphs are unified,

f) found is the center of gravity in the mass contained in the area of the resulting graph,

g) the $\mathrm{x}$-axis coordinate of the center of gravity is the recommended intervention $(X o=1.1753$ in Fig. 3).

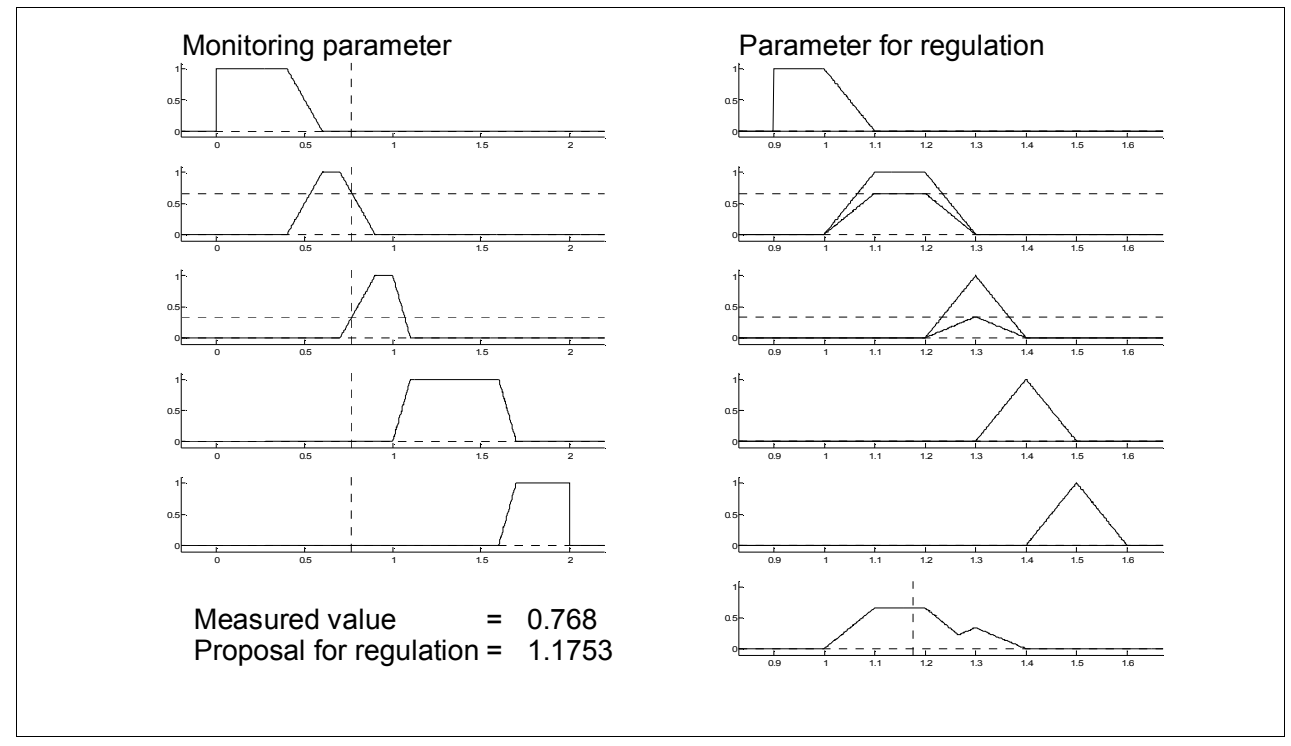

Figure 3 - Graphical depiction of the calculation of intervention 
The software Matlab was used for the calculations and drawings. Integrals used to calculate the coordinate of the center of gravity was obtained numerically using a modified rectangle method.

\section{MATHEMATICAL REASONING BEHIND THE CALCULATION}

Each of the ten regulation rules is an implication, where $A$ and $B$ are fuzzy sets. An example is the verbal statement (Novák, 2002; Bělohlávek, Dvořák, Jedelský, and Novák 1998):

If $Y$ is standard (Y3), then keep $\mathrm{X}$ on the standard level $(X 3)$. This regulation rule is the third mentioned rule in Table 3.

Every implication between fuzzy sets can be expressed as a set $A x B$ of pairs $(x, y)$ with degree of membership of $(x, y)$ in $A x B$ given by $A x B(x, y)=\min (A x, B y)$. This tells us the weight with which the value $x$ implies the value $y$.

The whole managerial algorithm can be formally expressed as

$$
\left(A_{1} \Rightarrow B_{1}\right) \vee\left(A_{2} \Rightarrow B_{2}\right) \vee \ldots \vee\left(A_{n} \Rightarrow B_{n}\right)
$$

or

$$
\left(A_{1} x B_{1}\right) \cup\left(A_{2} x B_{2}\right) \cup \ldots \cup\left(A_{n} x B_{n}\right)
$$

i.e.

$$
R_{1} \cup R_{2} \cup \ldots \cup R_{n}
$$

where

$$
R_{i}(x, y)=\min \left(A_{i}(x), B_{i}(y)\right)
$$

and

$$
R(x, y)=\max \left(R_{1}(x, y), \ldots, R_{5}(x, y)\right) .
$$

\section{CONCLUSION}

Automation of technological process management is a subject of intensive study. There is a variety of approaches to this issue. These approaches usually try to resolve a concrete problem, such as calculation of inputs into the process, which will ensure economically and technologically optimized outputs, or maximal robustness of the process.

We showed in this article a simple possibility of setting up an expert system whose great advantage is the use of operator's experience. The description of operator's work is, however, often burdened with the problem of formalization of such work as it is described verbally. Fuzzy sets are a suitable tool for such 
purposes. Setting regulation rules based on operator's experience, using fuzzy sets, is simple, and calculation of regulatory intervention is fairly simple as well. Further generalization of the described procedure is given by a process management with more than one input. The principle of such management remains essentially the same in this case.

\section{AKNOWLEDGEMENT}

This paper was elaborated within the frame of the specific research project No. SP2011/85 which has been solved at the faculty of Metallurgy and Material Engineering, VŠB-TU Ostrava with the support of the Ministry of Education, Youth and Sports in the Czech Republic.

\section{REFERENCES}

Bělohlávek, R., Dvořák, A., Jedelský, D., Novák,V. (1998). “Object Oriented Implementation of Fuzzy Logic Systems", In: Intelligent Systems for Manufacturing. Multi-Agent Systems and Virtual Organizations, Boston: Kluwer Academic Publishers, pp. 589-594.

Bělohlávek, R., Novák,V. (2002). "Learning rule base in linguistic expert system", Soft Computing, pp. 79-88.

Kelemen, J., Linday, M. (1996). Expertné systémy pre prax, Bratislava: SOFA.

Lin, S., He, Z. Y., Qian, Q. Q. (2010). "Review and development on fault diagnosis in power grid", Dianli Xitong Baohu yu Kongzhi/Power System Protection and Control 38 (4), pp. 140-150

Novák, V. (1986). Fuzzy množiny a jejich aplikace, Praha: SNTL.

Novák, V. (2002). "Models and submodels of fuzzy theories", In: Proc. IPMU 2002, Annecy, pp. 385-390.

Popper, M., Kelemen, J. (1989). Expertné systémy, Bratislava: Alfa.

Wang, J. L., Xia, L., Wu, Z. G., Yang, X. F., Li, Z. (2010). "State of arts of fault diagnosis of power systems", Dianli Xitong Baohu yu Kongzhi/Power System Protection and Control 38 (18), pp. 210-211 


\section{ABOUT THE AUTHORS}

Prof. RNDr. Josef Tošenovský, Ph.D.,VŠB-TU Ostrava, 17.listopadu, OstravaPoruba 708 33, Department of Quality Managemen, Czech Republic, e-mail: josef.tosenovsky@vsb.cz

RNDr. Břetislav Krček, Ph.D., VŠB-TU Ostrava, 17.listopadu, Ostrava-Poruba 708 33, Department of Mathematics, Czech Republic, e-mail: bretislav.krcek@vsb.cz

Bc. Lenka Monsportová, student at VŠB-TU Ostrava, 17.listopadu, OstravaPoruba 708 33,Czech Republic, e-mail: monsportova.lenka@seznam.cz

Ing. Filip Tošenovský, Ph.D., Faculty of Business Admnistration of Silesian University, Univerzitní náměstí 1934/3, Karviná 733 40, Department of Mathematics, Czech Republic, e-mail: tosenovskyfilip@opf.slu.cz 